\title{
Concentration of Radon in Indoor Air in Lalibela, Ethiopia
}

\author{
Tadesse Abate \\ Physics Department, Debre Tabor University, Debre Tabor, Ethiopia \\ Email address: \\ tadesseabate96@gmail.com

\section{To cite this article:} \\ Tadesse Abate. Concentration of Radon in Indoor Air in Lalibela, Ethiopia. Radiation Science and Technology. \\ Vol. 6, No. 1, 2020, pp. 7-11. doi: 10.11648/j.rst.20200601.12
}

Received: November 28, 2019; Accepted: December 25, 2019; Published: April 14, 2020

\begin{abstract}
The second largest cause of lung cancer is related to radon $\left({ }^{222} \mathrm{Rn}\right)$ and its progenies in our environment. Building materials, such as concrete, contribute to the production of radon gas through the natural decay of ${ }^{238} \mathrm{U}$ from its constituents. This Radon has been recognized as one of the major contributor to the natural radiation and health hazards in the human dwellings. Even lung cancer is expected if it is present in enhanced levels beyond maximum permissible (acceptable) limit. This thesis reports the measurements of indoor radon concentration in the Lalibela dwellings of the Amhara region in Northern Ethiopia using the cellulose nitrate (LR-115 type-II) plastic track detectors. Eleven cellulose nitrate films (LR-115 SSNTD) were distributed over the study area dwellings according to the fraction of the population. The exposure time was started from February $21 / 2013$ and lasted for 90 days. It is found that the values of radon concentration vary from 52.45 to $353.95 \mathrm{Bqm}^{-3}$ with the average value of $140.64 \mathrm{Bqm}^{-3}$. The effective dose rates have been calculated and found to vary from 1.38 to 9.34 $\mathrm{mSvy}^{-1}$ with over all mean value of $3.71 \mathrm{mSvy}^{-1}$. It is also found that mud houses (houses use unbaked bricks) have relatively lower indoor radon as compared to the houses which are made of the baked bricks and cement.
\end{abstract}

Keywords: Radon, Detectors, Indoor Air, Dwellings, Effective Dose, NaOH, Etching

\section{Introduction}

Radon is a naturally occurring radioactive gas generated by the decay of uranium and thorium bearing minerals in rocks and soils. Radon and its decay products are the major contributors to human exposure from natural radiation sources [1], and have been identified as the first leading cause of lung cancer for non-smokers whereas it is the second leading cause of lung cancer for the general populations. Radon-222 and radon-220 are the most common isotopes of radon, with the term "radon" typically referring to radon-222 and "thoron" to radon-220.

Radon (radon-222) has a half-life of 3.82 days [2], and originates from the uranium (uranium-238) decay chain. The half-life of thoron (radon-220), a product of the thorium halflife, thoron infiltration from the ground and subsequent migration from its production site to the immediate environment of people within a building is limited. Thus, while radon tends to be homogeneously distributed in indoor air, the thoron level varies significantly with distance from the source. One of the thoron decay product, lead-212 $\left({ }^{212} \mathrm{~Pb}\right)$, is relatively long-lived $(10.64 \mathrm{hr})$ allowing it time to migrate into the immediate environment of building occupants before further decaying to produce the beta $(\beta)$ and gamma $(\gamma)$-emitting isotope bismuth-212 (with a half-life of $60.6 \mathrm{~min}$ ). Therefore, unlike thoron gas, thoron decay products tend to be more homogeneously distributed in indoor air [3].

\section{Experimental Methods}

\subsection{The Study Area}

Saint Lalibela is a town in northern Ethiopia that is famous for its monolithic rock-cut churches. Lalibela is one of Ethiopia's holiest cities, second to Aksum (Axum), and is a center of pilgrimage for much of the country. Unlike Aksum, the population of Lalibela is almost completely Ethiopian Orthodox Christian. The layout and names of the major buildings in Lalibela are widely accepted, especially by the local clergy, to be a symbolic representation of Jerusalem. This has led some experts to date the current form of its churches to the years following the capture of Jerusalem in 1187 by the Muslim soldier Saladin. 

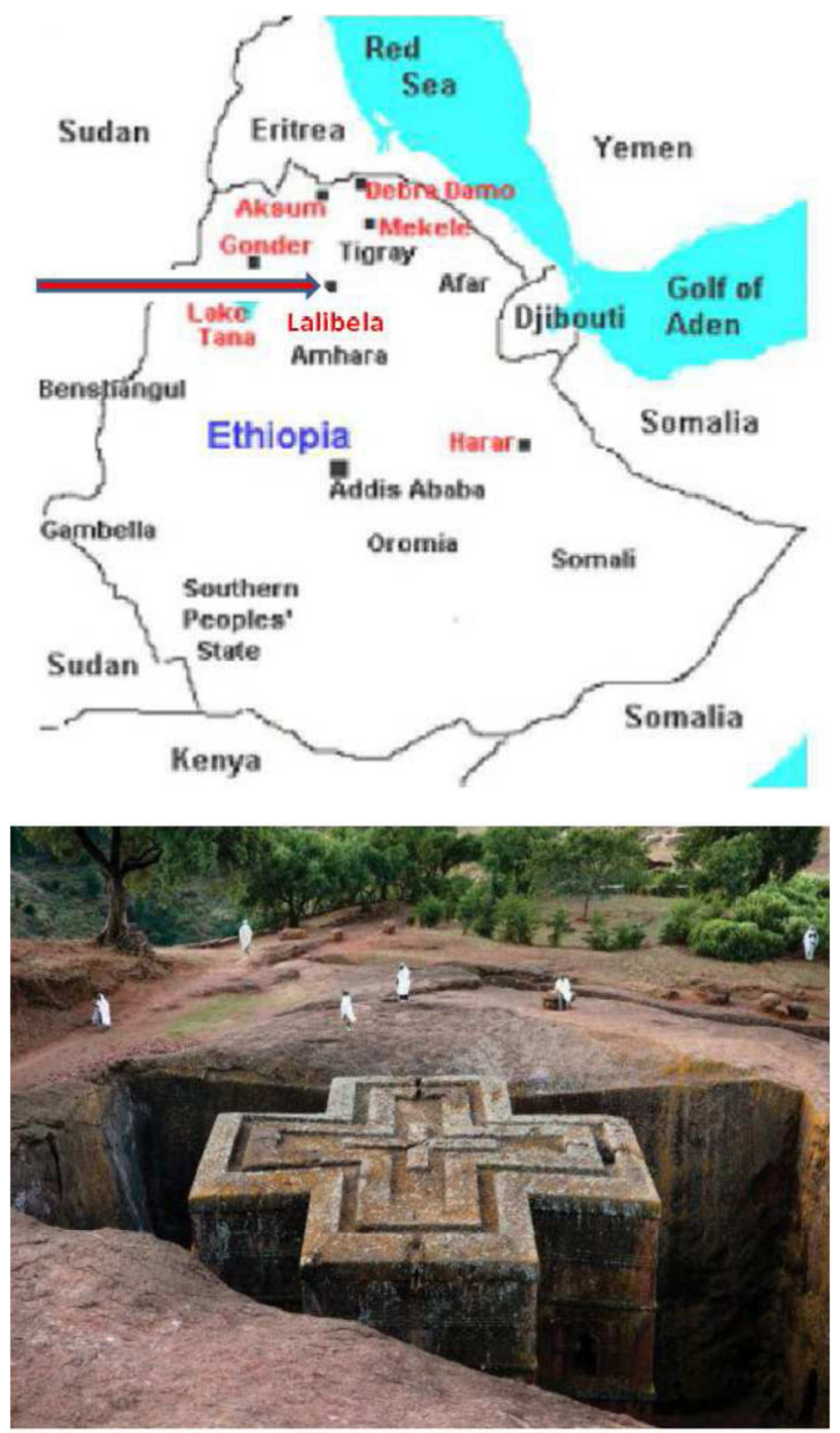

Figure 1. Geographical location of Lalibela in Ethiopia.

Lalibela is located in the Semien Wollo Zone of the Amhara ethnic division (or kilil) at 2,500 meters above sea level, and it has a latitude of $12^{\circ} 02^{\prime}$ North and longitude of $39^{\circ} 02^{\prime}$ East. It is the main town in Lasta woreda, which was formerly part of Bugna woreda.

\subsection{Experimental Techniques}

In the present work, LR-115 detectors have been used to get exposed with ${ }^{222} \mathrm{Rn}$ in a commonly used 'Bare Mode' technique. The detectors consist of an active layer of red cellulose nitrate on a $100 \mu \mathrm{m}$ clear polyester base substrate. The indoor radon $\left({ }^{222} \mathrm{Rn}\right)$ concentration has been studied in 11 houses. The dwellings under study were built, in general using different materials, like cement, sand, stones, and bricks, iron, and concrete as the construction materials. Several of these materials are expected to contribute significantly to sources of indoor radon. The experimental method for radon detection and measurement were based on alpha-counting of radon and its daughters. The 'bare mode' gives the values of radon and its progeny concentration together. The LR-115 Type II plastic track detectors of films size $3.00 \mathrm{~cm} x 2.00 \mathrm{~cm}$ were suspended inside the selected houses one meter below the roof. The films have been exposed in Lalibela city. After an exposure time of about 30 days, films were removed and etched in $2.5 \mathrm{~N} \mathrm{NaOH}$ solution at $(60 \pm 1)^{\circ} \mathrm{C}$ for 90 minutes and alpha tracks were counted by using optical microscope (James Swift (Olympus) England, at $400_{\mathrm{X}}$ magnification).

The area of one field of view was calculated by stage centimeter $(\mathrm{cm})$ and the track density was calculated in terms of number of tracks per $\mathrm{cm}-2$. The track densities were then converted into radon concentration by applying the conversion factor for LR-115 type II detectors in the 'Bare Mode'-technique as 1.12 tracks $\mathrm{cm}^{-2} \mathrm{~d}^{-1} / \mathrm{Bqm}^{-3}$ [4], which is known as sensitivity factor.

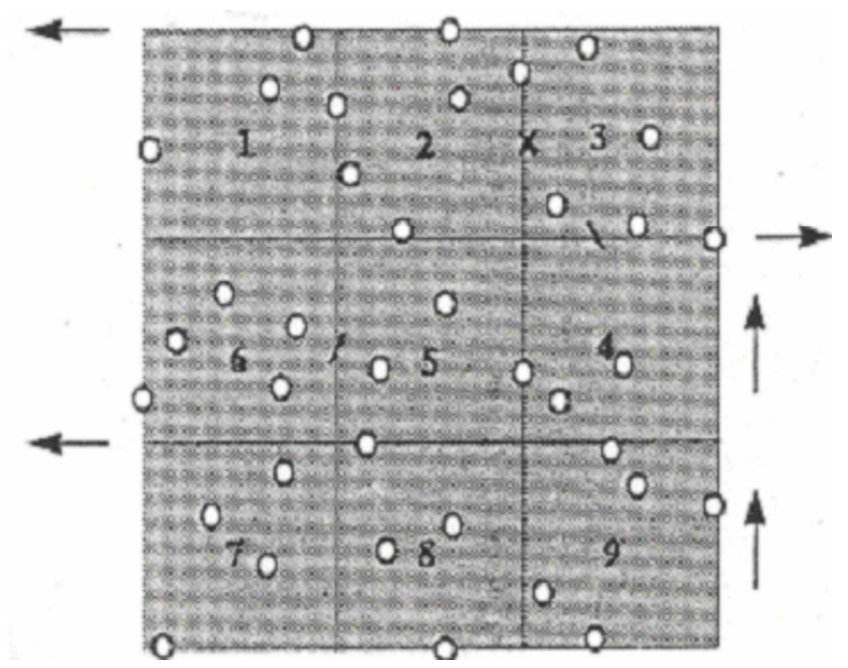

Figure 2. Tracks formation on RL-115 II type plastic track detectors after chemical etching.

The tracks registration represents the presence of alpha particles through small pits (tracks) on the surface of the detector. The tracks density is directly proportional to the total number of alpha particles. To consider these tracks, a calibration process is required to determine the calibration constant in units of tracks. Images of tracks can be enhanced by special techniques. For applications where only the measurement of track density is required, high contrast techniques have been developed which usually enlarge the track images using etching mechanism. In practice, to the most important parameters control the etching speed of the detectors are temperature, concentration of the etching solution and time.

\subsection{Calculation of Radon Concentration}

The solid state nuclear track detector is one of the most often used techniques for the measurement of Radon. Radon concentration $(\mathrm{C})$ in surrounding air is measured in terms of $\mathrm{Bq} / \mathrm{m}^{3}$, since the most regulatory reference levels are specified in this unit, and where carried out by the following equation:

$$
C_{R n}\left(B q m^{-3}\right)=\frac{3.7 \times C_{p}(m W L)}{F}
$$


where $\mathrm{F}=0.4$ for indoor, is the equilibrium factor, and $\mathrm{C}_{\mathrm{p}}=$ the potential alpha energy concentration.

\subsection{Health Risk Assessment}

Epidemiological assessment and physical dosimetry are the two major approaches, undertaken to estimate radiation dose associated to radon exposure. The first approach is based on equality of detriments (results of in harm or damage) from epidemiological determinations, whereas physical dosimetry estimates are model-dependent and derive conversion factors (CFs) from the analysis of information on aerosol size distribution, unattached fraction, breathing rate, fractional deposition in the airways, mucous clearance rate and location of the target cells in the airways. Radiation and tissue weighting factors are also taken into account. According to International Commission on Radiological Protection (ICRP), the tissue weighting factor for lung is 0.12 , and the radiation weighting factor for alpha particles is
20.

$$
D\left(\mathrm{mSvy}^{-1}\right)=\mathrm{C}_{\mathrm{Rn}}\left(0.17+9 \times F_{R}\right) \times 0.007
$$

The standard deviation for the present study was also evaluated by the following equation:

$$
\sigma=\sqrt{\frac{\sum_{i=1}^{n}\left(x_{i}-\dot{x}\right)}{N-1}}
$$

\section{Results and Discussion}

\subsection{Results}

Table 1 and figures 3 and 4 summarize the results of indoor radon concentration levels, and the effective absorbed dose measured in eleven different houses in Lalibela city, Ethiopia.

Table 1. The PAEC, indoor radon levels (values), and the annual inhalation doses recorded in the dwellings in Lalibela town (PAEC=Potential Alpha Energy

\begin{tabular}{|c|c|c|c|c|c|c|c|}
\hline $\begin{array}{l}\text { Sample } \\
\text { No. }\end{array}$ & Detectors code & Ventlation & Home Type & $\begin{array}{l}\text { Track } \\
\text { Density } \\
\end{array}$ & PAEC & $\mathbf{R n}_{\text {con }}\left(\mathrm{Bqm}^{-3}\right)$ & $\begin{array}{l}\text { Annual inhalation dose } \\
\left(\mathrm{mSvy}^{-1}\right)\end{array}$ \\
\hline 1 & G-01 & No & Poor (mud) & 114.04 & 9.56 & 85.63 & 2.26 \\
\hline 2 & MU-02 & No & Poor (mud) & 148.44 & 12.37 & 114.42 & 3.02 \\
\hline 3 & $\mathrm{AD}-03$ & No & Good & 67.56 & 5.63 & 52.01 & 1.18 \\
\hline 4 & B-04 & No & Good & 129.14 & 10.76 & 99.55 & 2.63 \\
\hline 5 & $\mathrm{~T}-05$ & No & Good (old) & 105.72 & 8.81 & 81.49 & 2.15 \\
\hline 6 & Z-06 & No & New & 459.24 & 38.27 & 353.995 & 9.34 \\
\hline 7 & E-07 & No & Poor (old) & 142.80 & 11.90 & 110.08 & 2.9 \\
\hline 8 & C-08 & Yes & New & 151.80 & 12.65 & 117.01 & 3.09 \\
\hline 9 & A-09 & No & Good & 418.92 & 34.91 & 322.92 & 8.52 \\
\hline 10 & MO-10 & No & New & 105.84 & 8.82 & 81.59 & 2.16 \\
\hline \multirow[t]{5}{*}{11} & L-11 & Yes & Good & 165.96 & 13.83 & 127.93 & 3.38 \\
\hline & & & & $\mathrm{AM}$ & 12.73 & 140.64 & 3.71 \\
\hline & & & & GM & 12.8 & 117.80 & 3.15 \\
\hline & & & & $\mathrm{SD}$ & 10.92 & 100.27 & 2.64 \\
\hline & & & & SD & 10.92 & 100.27 & \\
\hline
\end{tabular}
Concentration).

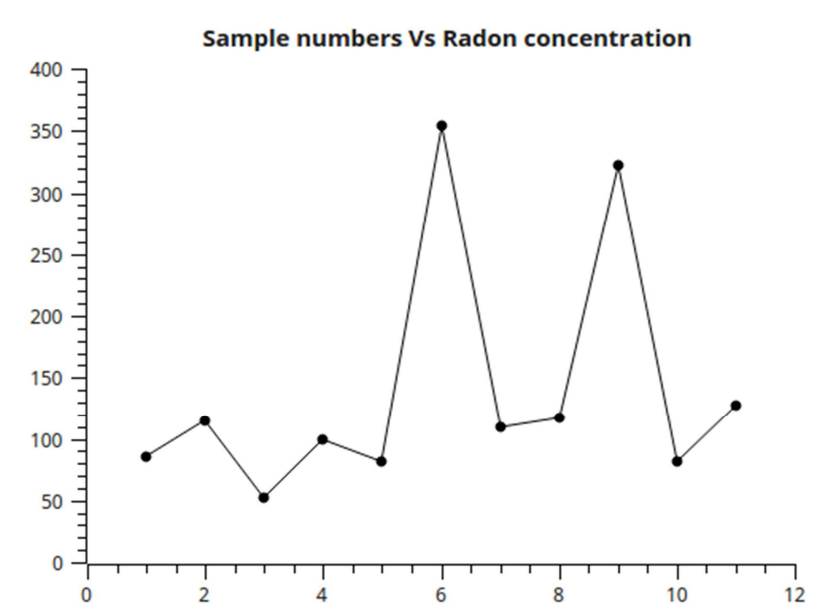

Figure 3. The Radon concentration with the corresponding samples on the used LR-115 type II plastic nuclear track detectors.

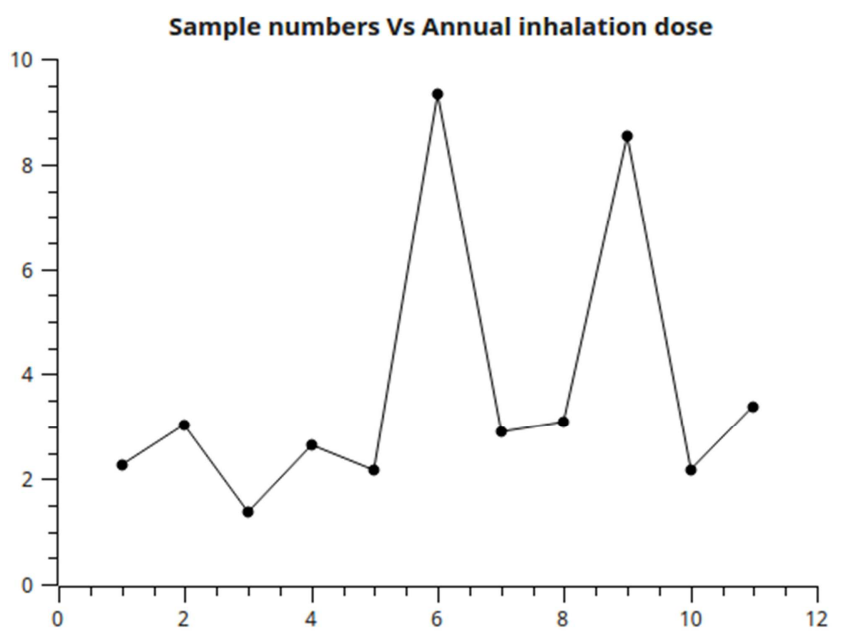

Figure 4. The effective dose rates for selected homes on the used LR-115 type II plastic nuclear track detectors. 


\subsection{Discussion}

The observations have been taken from February 21/2013 to March 22/2013. The data show that the indoor concentration obtained in the present investigations, varies from (52.45 to 353.95) $\mathrm{Bqm}^{-3}$, with overall average value 140.64 $\mathrm{Bqm}^{-3}$, which is lower than the recommended ICRP action level of $200-600 \mathrm{~B} \mathrm{qm}^{-3}$ [5]. The lowest value concentration was found as, $52.45 \mathrm{Bqm}^{-3}$, whereas the highest concentration was, $353.95 \mathrm{Bqm}^{-3}$. The annual effective dose equivalent from the corresponding measured radon concentration in different houses has been calculated using equation (2), which varies from (1.38 to 9.34) $\mathrm{mSvy}^{-1}$ with an average value of $\left(3.71 \mathrm{mSvy}^{-1}\right)$. In the present study, the annual effective doses received by the resident were in between the range of action level $\left(3-10 \mathrm{mSvy}^{-1}\right)$ recommended by ICRP (1993). The results show that the annual absorbed dose varies with the location. Values on the higher side may be attributed to the building materials, and poor ventilation (even though, there were the ventilators but not active because of the study area has moderate temperature), which usually play an important role in the indoor radon concentration. The lower values found may be attributed to the proper ventilation and building materials containing less amount of radium.

The results indicate that radon concentrations that we have investigated are significantly almost safe except two homes. Previous reports have indicated that ceramic is a potential source of radon, from where radon is mainly emerging from the decay of thorium and uranium in these materials. Another factor explaining the high levels of radon in these homes, are the poor ventilation status due to the relatively narrow openings. Using natural gas in houses, and supplying kitchens and bathrooms with water originated from underground sources is considered as a potential source for indoor radon.

The arithmetic and geometric mean of radon concentration, and doses in different homes in the city are tabulated in Table 1 . The average radon concentration was found to be lower than that of the EPA action level of $4 \mathrm{pCi} / \mathrm{L}$ while around $18 \%$ houses in the study area are found to have above the action level. Moreover, higher values are generally observed in dwellings of the reinforced concrete and cement (RCC).

It was observed that the strongest influence on indoor radon level is that of ventilation. To minimize the health hazards, it is necessary to characterize the sources. This requires attention to the rate at which radon is generated, the modes of transport and how it actually enter the indoor atmosphere. It is prudent to provide adequate ventilation to avoid building up of the daughter products in the dwellings.

Radon concentrations in homes depend on many factors such as house type, design and construction, local geology, soil permeability, etc. and can therefore vary significantly even between neighboring homes. The radon concentrations in an individual home can only be determined through measurement. The radon testing of a home should be followed by an assessment which includes the recommended actions to reduce the radon-related risk. For homes with radon concentrations above the reference level, remediation measures are always recommended.

Clear information on active radon reduction techniques should be provided to the householders. In addition, occupants of the house should be informed of the health effects of radon as well as the combined effect of radon and smoking. Information on radon and smoking can be used to further support tobacco control measures by public health authorities including [6-9]. The responsibility to reduce radon concentrations in a home normally rests with the householder.

The ventilation of occupied spaces may be done actively by using a fan or passively by operating windows or vents manually. There is limited evidence concerning the effectiveness of passive or natural ventilation for radon control. However, in moderate climates such as in Lalibela, ventilation may be used as an effective radon mitigation method [7]. Ventilation approaches to radon reduction are more common in mechanically ventilated schools and other large buildings than in small houses [10-16]. Fan-powered ventilation can reduce pressure differences between the soil and the occupied space, as well as dilute indoor radon after it enters.

\section{Conclusions}

Air, soil and water pollution are believed to be responsible for diseases. Natural radiation, Radon gas, present universally in different concentrations in air, soil and water has its harmful impacts on public health and causes lung cancer.

Data obtained for radon concentrations in the 11 dwellings of the Lalibela's city are summarized. The sampling distribution was almost homogeneous. The radon concentrations of 9 dwellings were lower than $148 \mathrm{~Bq} / \mathrm{m} 3$ and only 2 homes were higher than the guide level. As the results show, all radon concentrations range from 52.45 to $353.95 \mathrm{~Bq} / \mathrm{m}^{3}$ and the average standard deviation (SD) has been $100.27 \mathrm{Bqm}^{-3}$.

Etched track detectors for measuring radon are the 'Bare Mode' of choice, first, because they are passive and thus need no power supply and second because they measure total radon exposure, allowing averaging of the radon concentration over long time. From the analysis of the results of the indoor radon levels variation observed in the houses surveyed of the selected area may mainly be due to the local geological formations on which these houses are built as well as ventilation system of the houses. The present work revealed that the Lalibela town has relatively higher indoor radon levels. Mud houses (houses use unbaked bricks) have relatively lower indoor radon as compared to the houses which are made of the baked bricks and cement. As the cement used in Lalibela has relatively high radon concentration, annual arithmetic mean of the present study $140.64 \mathrm{Bqm}^{-3}$. 


\section{References}

[1] J. Chen, and D. Moir (2012), "Radiation Protection Bureau"; Health Canada, 2720 Riverside Drive; Ottawa K1A 0K9, Int. J. Environ. Res. Public Health 9, 286-293.

[2] G. Ielsch and D. Thieblemont (2000), "Radon $\left({ }^{222} \mathrm{Rn}\right)$ level variations on a regional scale": U. F. R. Sciences Techniques, LARAAH, 6 av. Le Gorgeu, B. P. 809, 29285 Brest cedex, France.

[3] I. Sulaiman and M. Omar (2010), "Environmental Radon/Thoron Concentration and Radiation Levels in Sarawak and Sabah"; Journal of Nuclear and Related Technology Vol. 7, No. 1.

[4] Burke, O., Long, S., Murphy, P., Organo, C., Fenton, D. and Colgan, P. A (2010), "Estimation of seasonal correction factors through Fourier decomposition analysis a new model" for indoor radon levels in Irish homes, J. Radiol. Prot. 433443.

[5] ICRP (1993), "Protection against Radon-222 at Home and at Work" Annals of the ICRP Vol. 23 No. 2.

[6] Synnott H. and Fenton D. (2005), "An evaluation of radon Reference Levels and radon measurement techniques and protocols in European countries"; European Radon Research and Industry Collaborative Concerted Action (ERRICCA2), European Commission Contract (FIRICT-2001-20142).

[7] WHO hand book (2007), "International Radon Project Survey on Radon Guidelines"; Programmes and Activities, Geneva, Swizerland.

[8] A. A. Leghrouz, M. M. Abu-Samreh, and A. K. Shehadeh (2017), "Measurements of Indoor Radon Concentration Levels in Dwellings in Bethlehem, Palestine"; Journal of Health Physics Society, vol. 104, pp. 163-167.

[9] M. K. Bhardwaj and M. Shakir Khan (2010), "Radium contents and radon exhalation rates studies in soil samples"; Recent trends in Radiation Physics Research, vol. 6, pp. 114-118.

[10] A. Abbasi and V. Bashiry (2016), "Measurement of radium226 concentration and dose calculation of drinking water samples in Guilan province of Iran"; International Journal of Radiation Research, Vol. 14, pp. 362-366.

[11] U.S. Saeed-Ur-Rahman (2018), "Measurement of Indoor radon levels; Natural Radioactivity and Lung Cancer Risks Estimation", Science of the Total Environment, vol. 626, pp. 867-874.

[12] P. Bossew (2003). "The radon emanation power of building materials, soils and rocks"; Application of Radiation Isolation, Vol. 59, PP. 389-392.

[13] M. Shakir Khan, A. H. Naqvi, A. Azam, D. S. Srivastava (2011), "Radium and radon exhalation studies of soil"; International Journal of Radiation Research, vol. 8, pp. 207-210.

[14] P. Szajerski, J. Celinska, H. Bem, A. Gasiorowski, R. Anyszka, P. Dziugan (2019), "Radium content and radon exhalation rate from sulfur polymer composites (SPC) based on mineral fillers"; Journal of Construction and Building Materials, vol. 198, pp. 390-398.

[15] F. A. As-Subaihi, S. R. Harb, T. A. Abdulgabar (2019), "Measurement of Radium Concentration and Radon Exhalation Rates of Soil Samples Collected from Selected Area of Aden Governorate, Yemen, Using Plastic Track Detectors"; International Journal of High Energy Physics, vol. 4, pp. 34-41.

[16] N. Sharma, J. Singh, S. C. Esakki, R. M. Tripathi (2016), "A study of the natural radioactivity and radon exhalation rate in some cements used in India and its radiological significance"; Journal of Radiation Research and Applied Science, vol. 9, pp. $47-56$ 